\title{
The Impact and Challenges of Integrating Micro Chemistry Experiments into E-Learning
}

\author{
Ruby Hanson \\ Department of Chemistry Education, UEW, Winneba, Ghana
}

\begin{abstract}
The impact of technology on society is as old as the emergence of radios televisions and telephones. Technology has spread from our homes to schools, work places, grocery shops and wherever human presence can be found in broader and more complex dimensions now. It is therefore important that educational institutions formally and consciously integrate innovative technology into modern day teaching. Some of the innovations could be in harnessing technology to solve the problem of large class size and nonavailability of science equipment in less resourced institutions and deprived communities. This study reports on the views and experiences of teacher-trainees in an undergraduate course, who participated in a hybrid online course integrated with micro chemistry equipment activities. In this study, Micro Chemistry Equipment (MCE) was distributed to 78 online chemistry teacher-trainees to enable them perform activities that accompanied their online curriculum materials at their convenience. The study was a designbased research which used triangulation procedures involving achievement tests, observations, questionnaires and semi-structured interviews to gather data for the analysis of the effectiveness of integrated MCE in an online course. The results of the study indicated a massive improvement in teacher-trainees' responses to chemistry concept-based questions in analytical chemistry. The study informed that supporting online chemistry learning with appropriate resources enhance conceptual understanding. The teacher- trainees also learned new ways of designing and conducting chemistry practical work as an added benefit from their participation in the study.
\end{abstract}

\section{Introduction}

There are various learning environments such as the face-to-face, online and blended or hybrid online environments, each of which requires diverse modes of teaching. The face-to face environment is the traditional mode of teaching, where an instructor is in a live contact with his students and interacts with them in real time and space. The teacher-presence is very prominent here. In a hybrid environment, the teacher is part of the time in contact with his students face-to-face and part of the time online with them synchronously or asynchronously. A typical online course, is a learning environment, where a learner interacts with a course material (also asynchronously or synchronously with a teacher or colleagues) without the real presence of a teacher. This mode of learning was introduced in 1999 by Jay Cross of Internet Time Group [1]. The online learning environment has become a hub of electronic teaching and learning activities and a variable alternative to traditional methods, and an apparent solution to the massification of higher institutions. Reviewed literature comments on the success of online Distance Education (DE) teaching and learning [2]. Ross [3] also reported that Indiana University integrated DE learning in chemistry with micro-scale labs, using home chemicals and supplies at reduced concentrations, with success. However, the use of e-learning has failed in some places due to inexperience on the part of staff and students in using the various platforms as well as the problem of work overload [4]. This is supported by a report from the Dublin Region Higher Education Alliance, DRHEA [5] which also reports the failure of an attempt to introduce e-learning due to disinterest by faculty and students.

Regardless these negative views on e-learning, one of the University of Education, Winneba's, corporate strategic plans in 2009, was to enhance the use of computer skills and information technology among faculty and trainees by the year 2013. In view of this efforts were made by the institution to design and infuse hybrid online courses into the existing traditional courses. In order to facilitate the adoption and implementation of the online courses to the full, lecturers were trained in the design of e-courseware (specifically the Moodle), while the institution's teacher trainees were educated in how to access courses. Chemistry teacher-trainees were supplied with micro chemistry equipment to facilitate the practical aspect of their online chemistry course. 
Research work by Hanson, Amedeker, Antwi and Oppong [6] revealed problems in pedagogy, curriculum, laboratories, equipment and consumables in teacher training institutions and the universities. Hanson and Acquah [7] in a similar study on the identification of secondary school students' conceptual understanding of some chemistry concepts found that the traditional approach to teaching adversely affected the way teachers taught chemistry and the way students understood and interpreted chemistry concepts. This resulted in many alternative concepts among chemistry students. Their report indicated that teachers had weak pedagogical skills while students had inadequate practical skills. However, the introduction of MCE through collaborative activities enabled students to improve upon their conceptual understanding of basic inorganic chemistry principles. In view of these findings, the need for the introduction of novel teaching methods that could solve the identified problems of noninteractive classes, lack of practical work, insufficient equipment and consumables were suggested. They recommended the introduction of more innovative and interactive approaches to teaching of chemistry.

Open access and online education has made it possible for many more people to engage in education as one big community of learners. Research evidence has confirmed that effective integration of technology can promote student engaged learning [8]. Many studies have reported on the benefits of integrating social media such as twitter, blogging and facebook into lessons to enhance learning, through technology $[9,10]$. Such integration is a comprehensive way of applying technology to the curriculum to improve teaching and learning. Few studies, however, have reported on the integration of e-learning or distance learning with real hands-on practical activities. Brooks [11], attempted to integrate micro scale experiments via internet in the United States of America to a group of 21 students. A micro chemistry equipment (MCE) laboratory component was included as part of a graduate course, which had seven (7) modules. The modules provided participants with opportunities to conduct small-scale experiments and discuss their outcomes with their classmates and teacher on a Moodle chat platform since hands-on science activities lead to minds-on learning.

During the last decade, science and teacher training curricula in Southern and Eastern Africa have as an innovation in teaching, adopted MCE activities in preference to traditional science activity teaching [12]. Micro chemistry equipment have been found to be very effective substitutes for traditional macro science equipment and more effective in enhancing conceptual understanding of science among learners [13, 14]. Thus, the time is ripe for science teachers to acquire sufficient micro scale activity skills in order to address issues related to pedagogical science teaching, save cost, and the environment $[15,16]$. This could be done in conjunction with modern technology to save not only cost but time as well; especially for adult learners and people who have to travel over long distances to institutions of learning.

The first working hypothesis for this study began with the fact that open source software is cheap, flexible for self-tutoring, readily available and easily accessible. It enables learners to become an intrinsic part of an academic community where they are able to discover and share knowledge with their peers. The second component in this study, the micro chemistry equipment (MCE) is a small set of laboratory equipment used for practical activities. It comprises a special microwell plate (hereby called the comboplate), some specially designed items such as lids for the wells to facilitate the preparation and use of gases and standard items such as plastic syringes and propettes. The propettes could be used as droppers or measures. Included is a micro stand which serves as a clamp stand, micro spatula for fetching solids and other resources for performing experiments on electrochemistry [17]. Figure 1 is a picture showing some of the typical equipment in a micro kit.

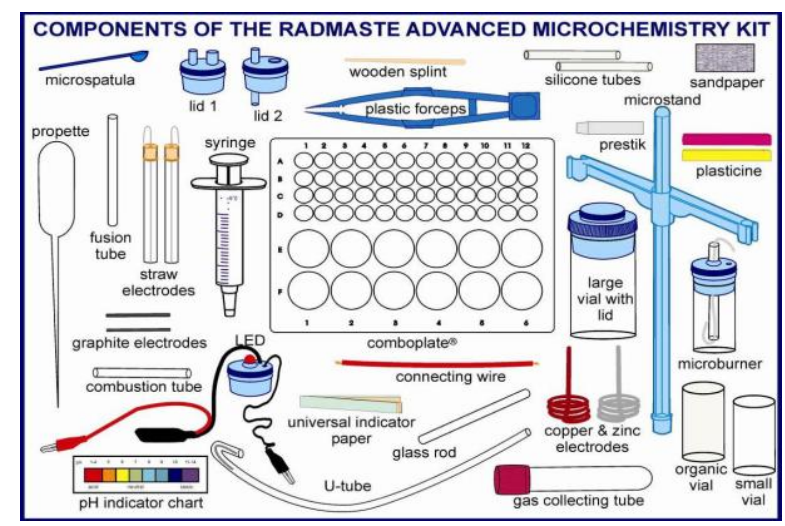

Figure 1: A picture of a typical MCE kit

The MCE kit, which performs virtually the same functions as the conventional laboratory glassware for analytical, qualitative and quantitative school laboratory activities., comes with an added advantage of being robust and cheap for use in all environments. This paper presents data gathered from a study of undergraduate teacher trainees who implemented and benefited from the use of MCE integrated into a hybrid online chemistry courseware as an intervention to identified problems in the teaching and learning of analytical chemistry in the University of Education, Winneba (UEW). The views and experiences of the beneficiaries would serve as a source of encouragement and information to future educators who would want to integrate real science activities into online courses. 


\section{Background}

In recent times, pedagogical integration of information communications technology (ICT) has become the focus of teaching and learning at almost all levels of formal education, particularly higher education $[18,8]$. Essuman and Appiah-Boateng [18] assert that tutoring and learning online require special skills and material to ensure that the purpose for which a situation is created is achieved. Teachers, thus, have to learn to design and implement e-courses with a lot of innovation. The provision of MCE could allow elearners to try out e-activities at their convenience in their homes, halls of residence and classrooms to enhance their real understanding of the theories and concepts through hands-on activities without being in a conventional laboratory [19]. Working in virtual labs is also another possibility of performing science activities, away from standard laboratories, but they are not as effective as real activities in forming sound, concrete concepts [13]. Although benefits of MCE and chemistry experimentation may be many, empirical evidence of its impact on classroom practice and e-learning to enhance concept understanding at the university level is limited. Most studies on MCE have concentrated on its economic aspect [20] and its use for conceptual development in primary and secondary schools [21, 22]. Hanson, Amedeker, Oppong and Antwi [6] used MCE to unearth and correct undergraduate teacher trainees' alternative concepts in some basic inorganic chemistry topics in Ghana. Generally, not much work has been done on the conceptual development of science principles in the universities. The few researched works indicated poor concept knowledge in topics such as acid-base, matter and molecularity [23], periodic chemistry, stoichiometry, nuclear chemistry, equilibrium reactions and the mole concepts [24] but not much was done about their correction. No data on these researched topics were found for Ghana; thus conducting such a study into the introduction of elearning coupled with MCE activities to unearth and correct undergraduate teacher trainees' alternative conceptions in analytical chemistry was found to be a challenging and interesting project.

Teaching and transfer of knowledge in this study was done in a hybrid mode. This means that lessons were partly delivered online and partly face-to-face. Hybrid learning combines asynchronous and synchronous elearning with face-to-face instruction. Some reasons for the innovation were to encourage trainees to be able to solve problems, demonstrate critical thinking, develop their reflective abilities, enhance their online research skills and work in groups. Other reasons were to integrate MCE-approach teacher training with concurrent real-life classroom teaching in chemistry, help trainees to better understand some chemistry concepts, attempt a solution at the emerging issues of large class size in UEW, lack of laboratories, lack of equipment and lack of consumables, which have also been observed by Liu [25] as emerging problems in education. The innovation was also expected to address in-class deficiencies, enable learners to review the entire learning content at their own pace and leisure and to find convenient times to work through their problems independently.

The objective for this kind of research rested on the assumption that there is always an essence in sharing of experiences with and in new situations for improvement.

\section{Statement of the problem}

It has become necessary to follow worldwide trends of reducing pressure on classroom and laboratory facilities as well as to solve the problem of massification in universities in an innovative and technologically modern approach. In a similar vein, new ways are being sought to support adult workers, young mothers, and learners who have to travel over long distances and wish to continue with formal education but cannot make time to be in regular full-time institutions. With continuing economic pressure in education and increased environmental awareness, the need for MCE-based activities has become very important so as to save time, cost, chemicals, and the environment as well as to allow the practice of science in all kinds of environments, especially in remote, deprived areas, without standard laboratories. The main purpose of this study was to find out about the impact and challenges of infusing MCE activities, as a support tool, into a hybrid chemistry e-course and explore its impact and challenges on student learning - as far as the understanding of chemical concepts were concerned. The main research question that guided the study was:

How would the introduction of e-learning, fused with the use of micro chemistry equipment help to enhance the learning of chemistry concepts among level 100 students?

\section{Purpose of the study}

The implementation of the MCE in a hybrid online course was intended to explore, design and evaluate the use of the MCE as a support tool of convenience for practical activities by online learners. In view of constraints of resources, time, space and environmental issues, the study introduced the MCE approach as a means to perform physical practical activities without the presence of a well-equipped laboratory or virtual laboratories. The study particularly looked at how the use of MCE would be feasible within a chemistry online environment. 


\section{Rationale for developing an online-course}

- To address in-class deficiencies

- For trainees to review entire content in their own time and at their own pace

- For trainees to work through their problems independently or through collaboration from a distance

- For flexibility in studying

- For flexibility in assessment

\section{Rationale for integrating MCE}

- Shorter time for preparation and clear away

- Reduce waste at source and encourage thoughts about waste management

- Increased safety

- Lower costs of chemical substances and equipment

- Smaller storage and work area

- Reduced reliance on intensive ventilation systems

- Shorter reaction period so more time for reflection, evaluation and communication

- Pleasant working atmosphere

- Useable in all environments

\section{Methodology}

A design-based research approach was used for this study. The design comprised three major phases. The first phase was to find out how feasible each of the interactive modes - the online course and the MCEwould affect trainees' conceptual understanding in chemistry. The case study tried to capture and interpret the themes and issues that emerged from the novel teaching and learning experiences of an MCE module and an online delivery course. This led to the development of an e-chemistry courseware integrated with MCE activities. Teacher-trainees in the study were supplied with MCE kits for use at home and taught how to access the online course. The second phase of the study focused on the implementation of the developed MCE-integrated chemistry courseware. The third phase of the study assessed the impact of the innovation on teacher trainees of UEW. This paper focused on the third phase of the study which is on the effectiveness of the innovation on the conceptual understanding of analytical chemistry principles among first year undergraduate teacher trainees in the University of Education, Winneba, Ghana.

\section{Participants}

A total of 51 male and 27 female chemistry teacher trainees aged between 17 and 28 years participated in the study. The selection of participants was purposive as the Researcher was the instructor for the analytical chemistry course [26].

\section{Design and Implementation of the Hybrid Moodle}

Materials for various topics were prepared for topical dissemination. Lesson notes, weekly assignments and quizzes as well as all other activities were prepared and mounted online. To avoid course work overload, the total number of hours available for use online and face-to-face sessions were worked out to fall within the time that would have been used by trainees in a traditional face-to-face lesson. Gagne's [27] instructional design and Salmon's [28] emoderation principles were used as guidelines to produce a high quality online instructional courseware. Ideas from Laurillard's [29] e-conversational framework model were incorporated in the chemistry emodel to create an online social presence. The outcome was vetted by the University's e-courseware coordinator. The integrated MCE practical activities were adapted from the Centre for Research in Mathematics, Science and technology (RADMASTE) in South Africa's educational resources and translated to accompany the online theory lessons. Participants were supplied with MCE kits to enable them perform handson activities outside conventional laboratories and classrooms when necessary.

An entire lesson/course was developed to cover a total of 30 hours. Each course credit is originally three (3) hours a week for 10 weeks. Students worked for 20 hours only online as one hour per week (that is 10 hours in all) was used for face-to-face discussions. Out of the 20 hours, students used six (6) hours to collaborate with their colleagues on chat and forum platforms. Fourteen (14) hours were allocated for personal research and reflection. A total of ten hours was used for lecturerstudent face-to-face interactions.

Participants were provided with clear directives on what to do each day and where to get academic and technical support from. Weekly assignments, practical activities, course manuals, tutorials and lesson notes were made available online. These were presented in different styles to avoid monotony. Some of the different presentation modes were word documents, power point presentations, online demonstrations, simulations and audio presentations. Information about web and course ethics were all provided.

\section{Instruments}

For the purposes of corroboration and triangulation, four instruments - achievement tests, observation, interview and a 15-item questionnaire were used to gather data. Simple MCE practical concept-based questions as well as online-practical based questions were developed to measure participants' conceptual 
understanding of analytical chemistry principles. The content of the test items included concepts related to calibration, separation, identification, extraction, distillation, chromatography, electrical conductivity and precipitation reactions. The test items were validated by senior colleagues in the field of chemistry education. The improved versions were used for both pre- and post-concept tests. The reliability of the test was 0.74 . In order to assess participants' opinions on the innovation a 15-item questionnaire was administered to find out if the new approach was interactive enough, unearthed their alternative concepts, enhanced better understanding and formation of sounder, concrete concepts, made learning more enjoyable and gave more opportunities for real time practical work practice. The cronbach alpha of the questionnaire was found to be 0.78. A student observation schedule was used to assess how well participants used the new learning approach during face-to face sessions to develop their concept, process and manipulative skills. Notes were also taken by the Researcher to enrich the observation schedules.

\section{Data collection}

Data was gathered from completed student questionnaire, achievement test scores, an observation schedule sheet from lesson delivery, opinions from a semi-structured interview and web-based practical assessment.

\section{Results and Findings}

The results of observations made in four face-toface lesson deliveries to ascertain how participants engaged with the MCE are presented in Table 1. The symbols,+ \pm , and - were used to indicate whether desired behaviours were observed fully, partially or not at all.

\section{Table 1: Observation results for the use of MCE in four practical sessions}

\begin{tabular}{|c|c|c|c|c|}
\hline \multirow[t]{2}{*}{ Trainee behaviour/activity } & \multicolumn{4}{|c|}{ In-class activities } \\
\hline & 1 & 2 & 3 & 4 \\
\hline $\begin{array}{l}\text { Relate prior knowledge to the day's } \\
\text { lesson }\end{array}$ & - & - & - & + \\
\hline $\begin{array}{l}\text { Understand what to do and form groups } \\
\text { to begin work }\end{array}$ & - & \pm & \pm & \pm \\
\hline Cooperation evident & - & + & + & \pm \\
\hline Groups interact with teacher as expected & - & - & + & + \\
\hline Evidence of reading with understanding & - & \pm & + & + \\
\hline $\begin{array}{l}\text { Evidence of working with apparatus and } \\
\text { materials }\end{array}$ & + & \pm & + & + \\
\hline $\begin{array}{l}\text { Materials obtained and activities started } \\
\text { with no fuss }\end{array}$ & - & \pm & + & + \\
\hline Discuss their outcomes in small groups & + & \pm & \pm & + \\
\hline $\begin{array}{l}\text { Understanding and interest in the lab } \\
\text { procedures and activities }\end{array}$ & \pm & \pm & + & + \\
\hline Ability to discuss outcomes coherently & & \pm & + & + \\
\hline
\end{tabular}

with their teacher

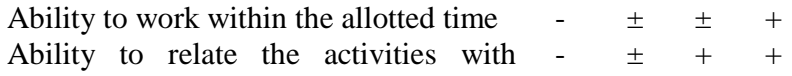
theory

Acknowledge wrong deductions and - \pm \pm+ work around it again
Use scientific terms and concepts with $-\quad \pm++$ meaning

Recap to confirm understanding of - \pm++ concept

Relate the newly learned/ concept in + \pm++ new situations to indicate permanent learning

-: behaviour not observed; \pm : behaviour partially observed; +: behaviour observed

From Table 1, it is evident that trainees exhibited proficiency of the use of the MCE in lessons 2, 3, and 4, and were able to use it to show their conceptual understanding of the principles of extraction, separation, the mole, stoichiometry and precipitation reactions through their responses and actions during activities through their behaviour. They were able to interpret instructions and set up their own activities correctly as more pluses $(+)$ were recorded for them in activity 4 .

Trainees' performance on the pre- and post-test is presented in Table 2. The results show their change in cognition with the use of MCE in the online course.

Table 2: Percentage scores for pre- and post-concept achievement tests

\begin{tabular}{lll}
\hline Scores $(\%)$ & \multicolumn{2}{c}{ Percentage of trainees } \\
\cline { 2 - 3 } & Pre-test & Post-test \\
\hline Above 80 & 0 & 6.41 \\
$70-79$ & 1.28 & 25.64 \\
$60-69$ & 2.56 & 19.23 \\
$50-59$ & 21.79 & 35.89 \\
$40-49$ & 24.35 & 5.13 \\
Below 40 & 50.00 & 7.69 \\
\hline
\end{tabular}

$(\mathrm{N}=78 ;$ Number of questions $=20)$

From Table 2, it is clear that $74.35 \%$ of the sample scored less than $50 \%$ in the pre-test while $25.63 \%$ scored above $50 \%$. In the post-test $12.82 \%$ had marks below $50 \%$ while $87.17 \%$ had over the $50 \%$ pass mark.

\section{Some identified misconcepts}

- Molarity was expressed as the mole of a solute in $100 \mathrm{~g}$ of a given solution

- The mole was calculated as mol=cv/1000 and used $\mathrm{dm}^{3}$ as $\mathrm{cm}^{3}$ for unit

- The mole ratio expression 1:1 was popularly and indiscriminately used in the face of other ratios like 1:2 
- The assertion that molar mass of a reactant determines the mass of product instead of the amount of reactant given in the problem

- Wrong expressions of reaction equations and formulae of products

- Units for molar mass expressed in moles

- Chemical reactions cease as soon as one reactant is used up

- Limiting reactants is based on mole ratios

- Mole ratio is dependent on concentration

- Doubling reacting solutions lead to a change in mole ratio

- Increasing concentrations of reacting species increases their mole ratios

- Concentration and acid strength are commensurate

- If the concentration of a weak acid is high it dissociates very well because it will have many 'hydrated $\mathrm{H}^{+}$' ions

These erroneous conceptions were gradually corrected by the trainees themselves as shown by an increase in post test scores in Table 2 and their improved practical activity scores in Table 3 .

In Table 3, results of trainees' mean performances in MCE prelab (PRL), post lab (POL) concept development $(\mathrm{CD})$ and the entire practical activities (Total) over time are presented.

Table 3: Results of mean class scores for $10 \mathrm{MCE}$ practical lessons

\begin{tabular}{|c|c|c|c|c|c|}
\hline Lab & Activity & $\begin{array}{l}\text { PRL } \\
(5)\end{array}$ & $\begin{array}{l}\text { POL } \\
\text { (5) }\end{array}$ & $\begin{array}{l}\text { CD } \\
(10)\end{array}$ & $\begin{array}{l}\text { Total } \\
(20)\end{array}$ \\
\hline 1 & $\begin{array}{l}\text { Measurements of } \\
\text { solutions }\end{array}$ & - & 1 & 6 & 7 \\
\hline 2 & $\begin{array}{l}\text { Preparing } \\
\text { solutions }\end{array}$ & 2 & 2 & 9 & 13 \\
\hline 3 & Distillation & 2 & 3 & 10 & 15 \\
\hline 4 & $\begin{array}{l}\text { Titrimetry- strong } \\
\text { acid against strong } \\
\text { base }\end{array}$ & 2 & 4 & 8 & 14 \\
\hline 5 & $\begin{array}{l}\text { Strong acid against } \\
\text { weak base }\end{array}$ & 2 & 3 & 9 & 14 \\
\hline 6 & $\begin{array}{l}\text { Amount of } \\
\text { substance }\end{array}$ & 3 & 4 & 10 & 17 \\
\hline 7 & $\begin{array}{l}\text { Precipitation } \\
\text { reactions }\end{array}$ & 3 & 5 & 9 & 17 \\
\hline 8 & Limiting reactants & 4 & 5 & 7 & 16 \\
\hline 9 & Redox titration & 3 & 4 & 9 & 16 \\
\hline 10 & Chromatography & 4 & 5 & 9 & 18 \\
\hline
\end{tabular}

From Table 3, it is evident that trainees had extensive practice with the MCE in various analytical chemistry topics and showed mastery of interpreting and conducting the activities with understanding. Their performance in their postlab scores are quite high, indicating that desired conceptual expectations were realised at the end of each MCE-concept based activity. Their efforts at conceptual development were quite high as seen from their mean concept development scores in column five of Table 3.

A questionnaire was administered to find out if trainees found the intervention as useful and if conceptual gains were made as results in Table 3 indicated. The responses to the questionnaire are presented in Table 4.

Table 4: Trainees' impressions about the intervention

\begin{tabular}{lll}
\hline $\begin{array}{l}\text { How the interactive online MCE } \\
\text { lessons helped to improve trainees' } \\
\text { conceptual understanding }\end{array}$ & $\begin{array}{l}\text { Positive } \\
\text { answers } \\
(\%)\end{array}$ & $\begin{array}{l}\text { Not sure } \\
\text { /negative } \\
\text { answers } \\
(\%)\end{array}$ \\
\hline $\begin{array}{l}\text { It was enjoyable and helpful in } \\
\text { understanding of analytical concepts }\end{array}$ & 76 & 24 \\
$\begin{array}{l}\text { The activities exposed my weakness } \\
\text { in understanding of some concepts }\end{array}$ & 70 & 30 \\
$\begin{array}{l}\text { It gave me confidence in designing } \\
\text { concept activities }\end{array}$ & 78 & 22 \\
$\begin{array}{l}\text { The social interaction enhanced my } \\
\text { conceptual understanding of } \\
\text { chemical principles }\end{array}$ & 65 & 35 \\
$\begin{array}{l}\text { It helped to develop better } \\
\text { conceptual understanding about } \\
\text { chemical analysis }\end{array}$ & 71 & 29 \\
$\begin{array}{l}\text { It helped to gain a better conceptual } \\
\text { understanding of qualitative analysis }\end{array}$ & 83 & 17 \\
$\begin{array}{l}\text { It enabled me to understand more } \\
\text { about the principle of separation }\end{array}$ & 86 & 14 \\
$\begin{array}{l}\text { It helped me to understand more } \\
\text { about the principle of extraction }\end{array}$ & 84 & 16 \\
$\begin{array}{l}\text { It enabled me to gain a better } \\
\text { conceptual understanding about } \\
\text { electrical conductivity }\end{array}$ & 87 & 13 \\
$\begin{array}{l}\text { It helped me to understand more } \\
\text { about the acid-base concepts }\end{array}$ & 87 & 13 \\
$\begin{array}{l}\text { It helped me to understand more } \\
\text { about the precipitation concept } \\
\text { It enabled me to confron my } \\
\text { misconcepts and correct them } \\
\text { through practice }\end{array}$ & 71 & 14 \\
$\begin{array}{l}\text { It helped me to understand how to } \\
\text { calibrate and its meaning }\end{array}$ & 81 & 19 \\
$\begin{array}{l}\text { The principle of distillation was } \\
\text { better understood }\end{array}$ & 91 & 09 \\
$\begin{array}{l}\text { It enabled me to have a better } \\
\text { conceptual understanding about data } \\
\text { analysis }\end{array}$ & 72 & 28 \\
\hline
\end{tabular}

Trainees' responses to the questionnaire indicated that they had positive experiences with the use of the MCE. A further probe into trainees' opinions on the usefulness of integrated MCE activities in their online course was obtained through a semi-structured 
interview. Some of the trainees' responses to the integrated MCE chemistry online course are presented below:

The MCE activities and other online assignments activities were easy to read and carry out

The MCE activities are in many parts. By the time you finish, if you have wrong ideas it becomes obvious so it helps you to test and correct your wrong ideas

The MCE activity materials are common things found in the environment so performing activities is easy; even at home. Replacing a lost item is easy; at almost no cost.

The reflection section of the MCE activities encourages critical thinking. The small kits sharpen one's observational and manipulative skills. Because the equipment is small, fewer chemicals are used so reaction times are shorter. Thus you have to be extra careful and critical when using the MCE to get accurate results.

The MCE increased my confidence in applying my initial knowledge about some concepts and activities. I was able to try out other activities on my own without fear of explosions. Now I know that when the concentration of reacting species increase, equals parts of reactants as in the dilute state will still react and so mole ratios will not increase but remain same. That's interesting.

When the activities are done during our face-to-face lessons it gives you an opportunity to collaborate with your colleagues. It makes our lessons activity-filled and interesting. We get help from each other to understand the topics well. We also collaborate on the internet

From the responses stated it is obvious that majority of the trainees enjoyed the use of the MCE in their online course. They found the activities to be interactive and a pathway to concept formation. An overall impression was that excited participants had positive impressions and experiences with the new MCEintegrated approach. This could be an indication of the success of the new approach- combining the MCE approach and online chemistry teaching into UEW's educational curriculum. They were happy at getting the opportunity to engage in chemistry activities at their convenience and on a reduced scale. They were particularly happy with the embedded safety of the MCE and felt encouraged to try out other activities on their own without the fear of causing explosions or hurting themselves. Responses from the semi-structured interview also revealed a corroboration of participants' own experiences with the MCE approach.

The trainees' impressions about the hybrid Moodle course gathered through semi-structured interviews were quite positive. They said that the Moodle 'enhanced their ICT competencies. They added that it increased their engagement with the course content, exposed them to a variety of learning and teaching skills and increased collaboration with their colleagues. More importantly, it enhanced their cognition and reflective capabilities. The following responses were given by some of the trainees:

The introduction to the online course increased my access to learning. I was able to look for more literature on all the topics by myself on the internet. It also made it possible to get closer to my lecturer than before. She was often online for us to interact with.

The hybrid course increased my awareness and demand for educational technology. It introduced me to various ICT techniques. I was able to get help from my quiet friends.

The new course exposed me to great opportunities for improving my reflective capabilities and learning skills. I hardly did any reflection after classwork; now I do it. It has been very worthwhile considering the in-depth skills gained and prospects for future course design and development

Because we could go online to do a lot of research and add new materials to what we were given in class, I got more learning materials which helped me to understand my course very well this semester. My scores on tests were all very high. I am so happy.

Learning online was more or less practical base, you are not just being taught but you also partake in that you interact with your colleagues and the instructor in a very interactive way each step of the lesson so that at the end of the day I realise that I have gained a better understanding than in the normal class.

\section{Discussion}

From the data gathered it was apparent that the new approach introduced trainees to newer, faster, easier to understand and exciting ways of conducting practical activities in the absence of a standard laboratory and expensive macro equipment. The innovative approach actively engaged them in the learning process and stimulated their interest in e-chemistry and practical activities. These observations about the MCE are consistent with the findings of Kolobe [22] and Mafumiko [16]. Positive experiences from the use of the e-learning platform are again consistent with findings from Hanson and Nsiah Asante [30] in contrast to the DRHEA's [5] observation. According to the DRHEA report, e-teaching and learning was not supported by faculty and staff for various reasons such as increased workload and possible loss of jobs. An analysis of the test data showed that learning gains were made for majority of the intended concepts to be learned in UEW. Thus, integrating MCE and online teaching into the traditional approach was viable and beneficial in the promotion of active learning environments. Observations made in this study supports work done in 
micro scale chemistry by Bradley (2000) and are also consistent with work by Dermircioglu, Ayas and Dermircioglu [31] which showed that students' involvement in practical activities led to greater understanding and interest in chemistry. In all, there was a significant quantitative increase of $61.53 \%$ in trainees' scores. This could be translated into positive gain in their conceptual understanding of analytical chemistry due to the innovation of integrating MCE into a hybrid online course.

\section{What participants said they gained from the study}

Participants said that it was easy to learn the use of MCE and new ways of doing activities due to valuable learning opportunities. They tried out new designs without fear and repeated activities as often times as they wished for reinforcement of concepts because results of the activities were accessed in relatively shorter times, as compared to the traditional method. They added that they enjoyed the electronic discussions due to its social collaborative aspect and prompt feedback. Lessons were student-centred. They were structured to enable trainees to discover their own errors and correct them with ease and confidence. For example, a trainee said that she was able to distinguish between the terms 'elution', 'eluate' and 'eluent' from the simple chromatographic activity that she performed. Another said that he understood and could explain why doubling a reaction solution had no effect on the reaction equation and mole ratios.

\section{Problems encountered}

A few problems were encountered with the online course in general. Some participants lacked the necessary computer skills to be able to navigate through the course with ease, regardless the pathway instructions given to the class. Others had difficulty making time to stay abreast with their colleagues. These problems appeared to be transient and superficial. The semistructured interview with the group showed that a few participants $(8 \%)$ procrastinated and did not tackle their activities until several weeks later.

\section{Conclusion}

This study was undertaken to explore the possibilities of integrating MCE activities into blended learning in order to promote a more active learning environment to enable teacher trainees to improve on their understanding of analytical chemistry concepts. It could be concluded from the studies carried out that the integrated MCE hybrid online course exposed trainees to new ideas, opportunities and resources for enhancing their conceptual understanding of analytical chemistry concepts. Thus, the teacher trainees were able to give better reasoned responses to questions on some of the observations and conclusions that they made in their study of analytical chemistry. Since preservice teachers would be teaching chemistry in high schools, it is of paramount importance that they eliminate their alternative conceptions through the help of their instructors who should employ new teaching strategies based on conceptual change models [32]. Integration of a course in teaching education programmes based on the identification of students' alternative conceptions as well as methods to correct them would imply the application of conceptual change strategies. This would enhance positive conceptual formation in students.

The findings so far suggest that using hybrid online tutoring coupled with MCE curriculum materials and activities are feasible for use in teaching institutions. Online teaching and learning addresses more learning outcomes which override challenges which may be encountered in its practice. The hybrid approach to teaching and learning was appraised as an effective teaching mode by participants. The integrated MCE approach afforded the participants an added advantage of convenient lab work. This further enhanced their practical skills and learning potentials.

\section{Recommendation}

It is recommended that more e-courseware integrated with micro hands-on activities should be deployed by other science lecturers to make the innovation a total success. However course goals, content and activities should be explicitly defined to avoid confusion in students' attempt to interpret the course instructions. There should also be an efficient support system. All chemistry online students should not only be supplied with the MCE kits but replacement parts and chemicals when necessary. Finally, websites and links should be checked regularly to ensure their availability for student access.

\section{References}

[1] Matei, A, and C Vrabie. "E-learning platforms supporting the educational effectiveness of distance learning programme: A comparative study in administrative science." ProcediaSocial and Behavioural Sciences 93, no. 1 (2013): 526-530.

[2] Langford, D. A. "Case study of development of distance learning." Journal of Professional Issues in Engineering Education and Practice 120, no. 4 (1994): 333-340.

[3] Ross, L. R. "Educators overcome difficulties with patnerships, 'distance learning'." Chemical and Engineering News 72, no. 37 (1994): 35-37. 
[4] Seery, M. K. "Moving an in-class module online: a case study for chemistry." Chemistry Education Research and Practice 13 (2012): 39-46.

[5] DRHEA. "Enhancement of Learning: Enablinge-Learning and Blended Learning."

http://www.drhea.ie/enhancement_audit.php. 2009.

[6] Hanson, R, M.K Amedeker, E Oppong, and V Antwi. "Using Microchemistry Activities to Improve Pre-service teachers' Conceptions of Some Inorganic Chemistry Topics." International Journal of Educational Administration 3, no. 1 (2011): 19-40.

[7] Hanson, R, and S Acquah. "Enhancing concept understanding through the use of microchemistry equipment and collaborative activities." Journal of Education and Practice 5, no. 12 (2014): 120-130.

[8] Wang, Q., and H. L. Woo. "Systematic planning for ICT integration in topic learning." Educational Technology and Scociety 10 , no. 1 (2007): 148-156.

[9] Thoms, B. "Student perceptions of microblogging: Integrating twitter with blogging to support learning and interaction." Journal of Information Technology Education:Innovations in Practice 11 (2012): 179-197.

[10] Thoms, B. "A dynamic social feedback system to support learning and social interaction in higher education." IEEE Transactions on Learning Technologies 4, no. 4 (2011): 340352.

[11] Brooks, D. W. Web Teaching. New york: Plenum Press, 1997.

[12] AJCE. "Microscale and Low-Cost Chemistry." Edited by T Engida. African Journal of Chemical Education (Federation of African Societies of Chemistry) 2, no. 1 (Special Issue) (January 2012): 1-60.

[13] Huang, Z. "Study on Micro-organic Chemistry Experiment Teaching." Journal of Guangxi University fo Nationalities, 2007: 2-6.

[14] Engida, T. "Microscale and Low-cost Chemistry." African Journal of Chemical Education 2, no. 1 (2012): 1-2

[15] Bradley, J. D. ""Science Education at the RADMASTE Centre: The role of a University in development." In Science and Environment Education: Views from developing countries, edited by S Ware, 141-150. Washington DC: World Bank, 1999.

[16] Mafumiko, F. M. S. "The Potential of Micro-scale Chemistry Experimentation in enhancing teaching and learning of secondary chemistry: Experiences from Tanzanian Classrooms." NUE Journal of International Cooperation 3 (2008): 63-79.

[17] Bradley, J. D. The micro-science project and its impact on pre-service teacher education. Washington, D. C.: The World Bank, 2000
[18] Essuman, S. O, and P Appiah-Boateng. "Faculty and students' collaboration in an online courseware development: Lessons and challenges." e-Learning Innovations conference and Expo. Nairobi, Kenya, 2013.

[19] Bates, A. W. T. Technology, open learning and distance education. London and New York: Routledge, 1995.

[20] Rayner-Canham, G. "Microscale methods in general chemistry." Education in Chemistry 11 (1994): 68-70.

[21] Mafumiko, F. M. S. Using microscale experimentation as a catalyst to improve the curriculum in Tanzania. Enschede: Kluver, 2006

[22] Kolobe, L. Introduction of RADMASTE Microchemistry kits in disadvantaged schools in Gauteng: A case study. MSc Research Report, University of Witwatersrand, Johannesburg: Faculty of Science, 1998

[23] Cros, D, M Mauvan, M Chastrette, J Leher, and M Fayol. "Conceptions of first-year university students' of the constituents of matter and the notions of acids and bases." European Journal of Science Education 8, no. 3 (1986): 305313.

[24] Peterson, R. F. "Tertiary students' understanding of covalent bonding and structure concepts." Australian Journal of Chemical Education 6 (1993): 61-72.

[25] Liu, D. Teaching Chemistry on the Internet. Thesis, University of Nebraska, Lincoln: Centre for Curriculum and Instruction, 1996

[26] Cohen, L, L Manion, and K Morrison. Research Methods in Education. 7th. New York: RoutledgeFalmer, 2011.

[27] Gagne, R. The conditions of learning. New York: Holt, Rinehart \& Winston, 1965.

[28] Salmon, G. E-moderating; The Key to Teaching and Learning Online. London: Kagan Page, 2002.

[29] Laurillard, D. Rethinking University Teaching. 2nd. London: Routledge Falmer, 2002.

[30] Hanson, R, and J Nsiah Asante. "An exploration of experiences in using the hybrid Moodle approach in the delivery and learning situations at the University of Education, Winneba, Ghana." Computational and Mathematical Methods in Science and Engineering. Vanderbijlpark, Gauteng: Vaal University of Technology, 2013.

[31] Demircioglu, G, A Ayas, and H Demircioglu. "Conceptual change achieved through a new teaching program on acids and bases." Chemistry Education Research and Practice 6, no. 1 (2005): 26-51.

[32] S evgi, A., A Nurdane, B. Yezdan, C. D. Ayla, and B Oktay. "The contribution of Constructivist Instruction Accompanied by Conceptual Understanding of Chemistry in the Laboratory Course." Journal of Science Education and Technology 18 (2009): 518-534. 